\title{
An Analysis of Quadrupole Splitting of the Mössbauer Spectra of Ferritin and Iron-Dextran Complexes in Relation to the Iron Core Microstructural Variations
}

\author{
M. I. Oshtrakh ${ }^{\mathrm{a}}$, O. B. Milder ${ }^{\mathrm{b}}$, V. A. Semionkin ${ }^{\mathrm{b}}$, P. G. Prokopenko ${ }^{\mathrm{c}}$, A. B. Livshits ${ }^{\mathrm{d}}$, \\ A. A. Kozlov ${ }^{\text {, }}$, and A. I. Pikulev ${ }^{\text {b }}$ \\ ${ }^{a}$ Division of Applied Biophysics, Faculty of Physical Techniques and Devices for Quality Control, \\ Ural State Technical University, Ekaterinburg, 620002, Russian Federation \\ ${ }^{\mathrm{b}}$ Faculty of Experimental Physics, Ural State Technical University, Ekaterinburg, 620002, \\ Russian Federation \\ ${ }^{c}$ Faculty of Biochemistry, Russian State Medical University, Moscow, Russian Federation \\ ${ }^{\mathrm{d}}$ Hematological Scientific Center of the Russian Academy of Medical Sciences, Moscow, 125167, \\ Russian Federation
}

Reprint requests to Dr. M. I. O.; Fax: +7(3432) 74-38-84,

E-mail: oshtrakh@mail.utnet.ru or oshtrakh@soek.sco.ru

Z. Naturforsch. 57 a, 566-574 (2002); received April 4, 2002

Presented at the XVIth International Symposium on Nuclear Quadrupole Interactions, Hiroshima, Japan, September 9-14, 2001.

\begin{abstract}
Mössbauer spectra of human liver ferritin and some pharmaceutically important iron-dextran complexes as ferritin models were measured at $87 \mathrm{~K}$ (frozen solutions) and at both 87 and $295 \mathrm{~K}$ (lyophilized forms). The Mössbauer spectra consisted of paramagnetic doublets only. However, the spectral line shapes were not Lorentzian and these Mössbauer spectra were better fitted using a superposition of two or more quadrupole doublets or using a distribution of quadrupole splittings. The differences of the maximal quantity of quadrupole doublets for better fitting of various Mössbauer spectra of ferritin and iron-dextran complexes were compared with the fitting using the distribution of quadrupole splitting for additional analysis. It is possible that variations of the quantity of quadrupole doublets for better fitting of Mössbauer spectra of ferritin and iron-dextran complexes may be related to heterogeneous iron cores in the samples. This heterogeneity is supposed to be different for various samples and changed for lyophilized samples and for frozen solutions as well as for various temperatures.
\end{abstract}

Key words: Ferritin; Iron-Dextran Complexes; Mössbauer Spectroscopy; Paramagnetic Iron Core; Quadrupole Splitting.

\section{Introduction}

Ferritin is an iron storage protein which consists of a polynuclear hydrous ferric oxide core (average composition $(\mathrm{FeOOH})_{8} \cdot \mathrm{FeO} \cdot \mathrm{OPO}_{3} \mathrm{H}_{2}$ ) with up to about 4500 iron atoms, surrounded by a multisubunit protein shell (Fig. 1, a) [1, 2]. A core structure was proposed earlier [3] with hexagonal symmetry in which iron atoms are coordinated to oxygen in a flattened octahedral arrangement (Fig. 1, b). The plane with iron atoms lies between two planes of approximately closed-packed oxygen. The sets of O-Fe-O layers are only weakly bound to each other to form the three-di- mensional structure. In this model each plane of iron atoms terminates with a phosphate group at the coreprotein interface [1]. Schemes of possible crystallites packing in the core are shown in Fig. 1, c. However, there is no clear explanation of the structure of the ferritin iron core yet. Iron-dextran complexes (IDC) are pharmaceutically important models of the iron storage protein ferritin. They are used or being developed as drugs for treatment of iron deficiency anemia. IDC consist of the FeOOH core with dextran shell. EXAFS study of ferritin and iron-dextran showed that the near-neighbor environment around the average iron atom is identical in both samples [4]. However, 

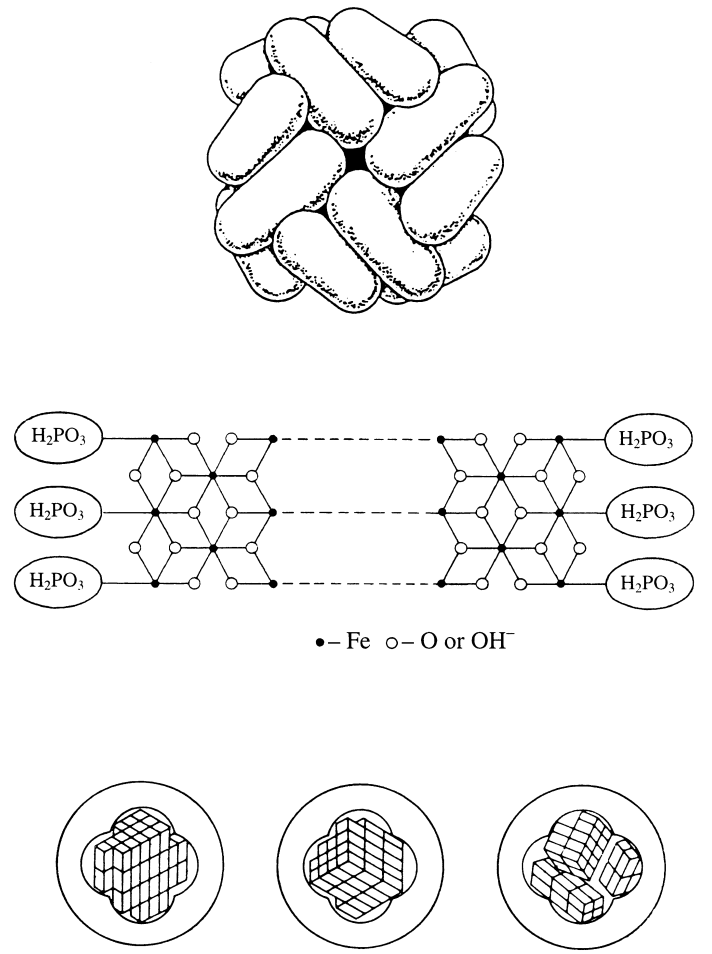

Fig. 1. The structure of ferritin: $\mathbf{a}$ - ferritin molecule (multisubunit protein shell surrounding the core); $\mathbf{b}$ - hydrous ferric oxide layer in the core; $\mathbf{c}$ - possible packing of crystallites in the core.

an electron diffraction study demonstrated that ferritin contained the iron core in a form like mineral ferrihydrite $\left(5 \mathrm{Fe}_{2} \mathrm{O}_{3} \cdot 9 \mathrm{H}_{2} \mathrm{O}\right)$ while the iron-dextran complex contained the iron core in a form like akaganéite $(\beta-\mathrm{FeOOH})[5]$. A recent electron diffraction study of ferritin showed that the iron core in the form of mineral ferrihydrite was not unique and some minor phases similar to the iron oxides magnetite, hematite, etc. were found [6].

Mössbauer spectroscopy was widely used to study of the iron core in ferritin and IDC [7 - 28]. The results of these studies showed that ferritins and iron-dextran complexes from various sources demonstrated differences of Mössbauer spectra and parameters related to different core sizes and microstructural variations of the iron cores due to different crystallinity. It is well known that the shape of Mössbauer spectra of various hydrous ferric oxides is non-Lorentzian. Several reviews regarding the Mössbauer study of iron oxides and oxyhydroxides pointed out that the paramagnetic room temperature Mössbauer spectra of these materials were better fitted by using more than one quadrupole doublet or using a distribution of quadrupole splitting [29 - 31]. In this work we analyze the paramagnetic Mössbauer spectra of human ferritin and some IDC, using fits with superposition of several quadrupole doublets or with a distribution of quadrupole splitting.

\section{Experimental}

\subsection{Materials}

Ferritin in lyophilized form from normal human liver was prepared by a method [32] with three fold recrystallization of the protein. Purified ferritin (more than $95 \%$ ) contained about $20 \%$ of bound iron. Electrophoresis of the obtained human liver ferritin in $7.5 \%$ polyacrylamide gel showed three immunochemically identical isomers in zone $\alpha_{2}$ and $\gamma$-globulins: monomer of $450 \mathrm{kDa}$, dimer $900 \mathrm{kDa}$ and multimer (more than $2000 \mathrm{kDa}$ ) [33]. The same electrophoresis of ferritin in denaturation conditions with sodium dodecil sulphate and further reduction with $\beta$-mercaptoethanole showed the presence of one polypeptide chain with a molecular weight of $18.7 \mathrm{kDa}$ [34]. To obtain a ferritin solution the lyophilized sample was dissolved in physiological solution and immediately frozen by liquid nitrogen.

The development iron-dextran complex IDC3P was prepared by adding $\mathrm{FeCl}_{3}$ to a dextran $(60000 \mathrm{Da})$ solution with $18 \% \mathrm{H}_{2} \mathrm{O}_{2}$ and heating at $60{ }^{\circ} \mathrm{C}$ during $1 \mathrm{~h}$. The $\mathrm{pH}$ of the solution was changed to 8.0 by adding of $\mathrm{Na}_{2} \mathrm{CO}_{3}$. Then solution was centrifuged and filtrated using Millipore filters $(0.8 \mu \mathrm{m}+0.45 \mu \mathrm{m}+$ $0.22 \mu \mathrm{m}$ ). The solution was concentrated using membranes PTGC 000 C 5 with transmission limit of globular protein with $10000 \mathrm{Da}[27,28]$. We also used the industrial pharmaceutical IDC product Imferon (Fisons, UK). Both IDC samples were in solution and in lyophilized form.

\subsection{Mössbauer Spectroscopy}

Mössbauer spectra were measured with the constant acceleration computerized precision spectrometer that was part of a multi-dimension parametric Mössbauer spectrometer SM-2201 [35]. The noise of the velocity signal of the spectrometer was $1.5 \times 10^{-3} \mathrm{~mm} / \mathrm{s}$, the drift of the zero point velocity 

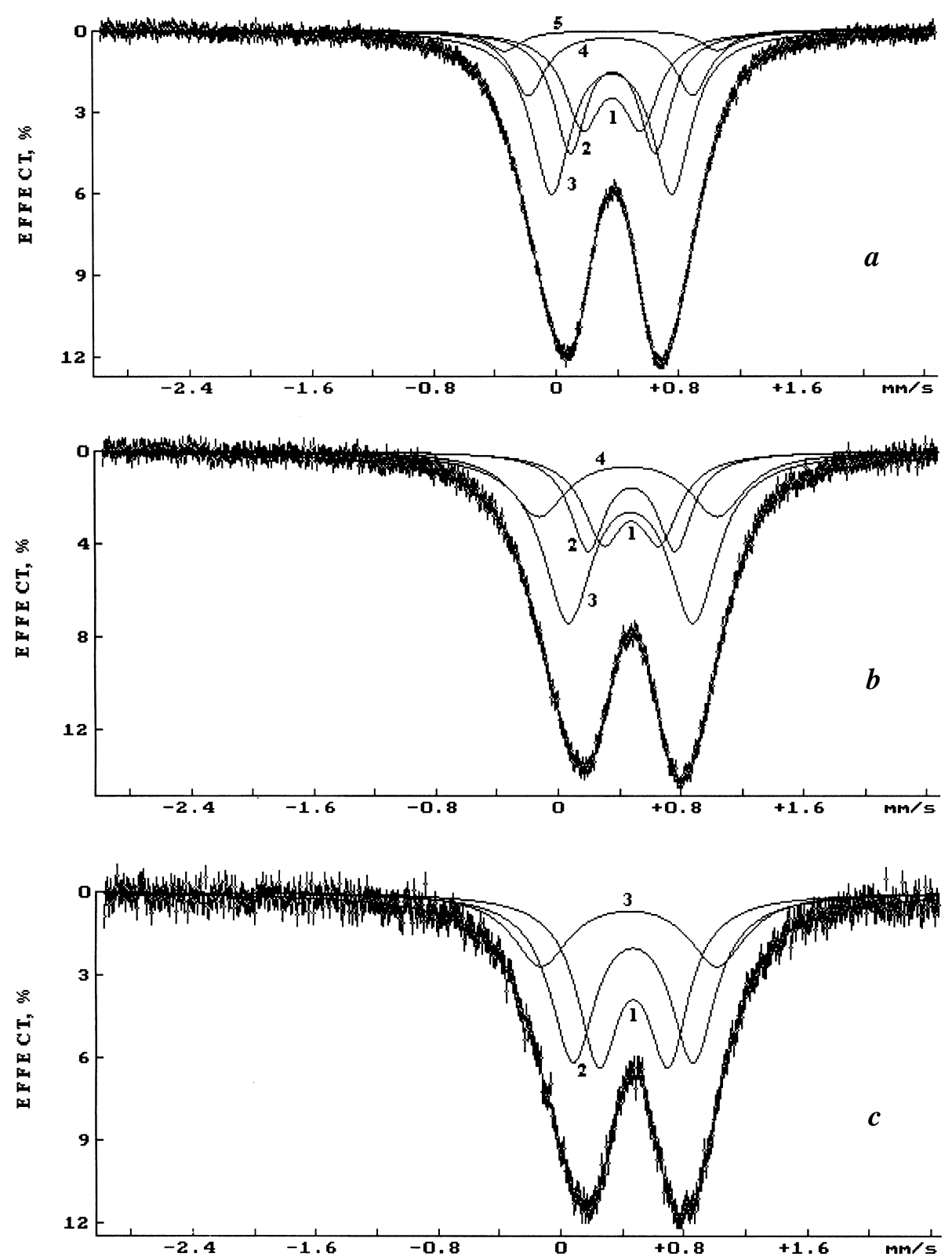

Fig. 2. Mössbauer spectra of human liver ferritin: $\mathbf{a}$ - lyophilized form, $T=295 \mathrm{~K}$; $\mathbf{b}-$ lyophilized form, $T=87 \mathrm{~K}$; $\mathbf{c}-$ frozen solution, $T=87 \mathrm{~K}$. Continuos lines marked with numbers from 1 up to 5 indicate a maximal number of quadrupole doublets needed for better fit.

was $\pm 2.6 \times 10^{-3} \mathrm{~mm} / \mathrm{s}$, the nonlinearity of the velocity signal was $0.01 \%$, the harmonic distortion factor was $0.005 \%$ for the frequency band in the range of $0-1120 \mathrm{~Hz}$. The parabolic distortion of the spectra was not larger than $0.1 \%$ of the statistical rate which was in the range from $1.1 \times 10^{5}$ to $1.3 \times 10^{6}$ counts per channel. A $2.5 \times 10^{9} \mathrm{~Bq}^{57} \mathrm{Co}(\mathrm{Cr})$ source was used at room temperature.

Mössbauer spectra of ferritin, IDC3P and Imferon in lyophilized form and frozen solutions were measured at $87 \mathrm{~K}$, using a liquid nitrogen cryostat. Additionally, Mössbauer spectra of lyophilized samples 
were measured at room temperature. Sodium nitroprusside was used as standard absorber. Mössbauer spectra of ferritin and IDC were computer fitted with the least squares procedure using Lorentzian line shape. The Mössbauer hyperfine parameters (isomer shift $\delta$, quadrupole splitting $\Delta E_{\mathrm{Q}}$ ) were determined. Additionally, all Mössbauer spectra were fitted using the program of the distribution of quadrupole splitting. The values of isomer shift are given relative to $\alpha-\mathrm{Fe}$ at $295 \mathrm{~K}$.

\section{Results}

The Mössbauer spectra of ferritin, IDC3P and Imferon were usual quadrupole split doublets. These spectra indicated the paramagnetic state of iron at both 295 and $87 \mathrm{~K}$. The spectrum of the frozen Imferon solution contained a weak additional quadrupole doublet with high values of $\delta$ and $\Delta E_{\mathrm{Q}}$ indicating the presence of a small amount of $\mathrm{Fe}^{+2}$ impurity in the sample. As the first step, all Mössbauer spectra were fitted by the least squares procedure using one quadrupole split doublet. The Mössbauer hyperfine parameters are given in Table 1 in comparison with some literature data. However, this fit was not satisfactory due to non-Lorentzian absorption line shapes in the Mössbauer spectra. Therefore we fitted further these spectra with various numbers of quadrupole split doublets and using the distribution of quadrupole splitting for comparison.

Table 1. Mössbauer hyperfine parameters of human ferritin and iron-dextran complexes obtained using one quadrupole doublet approximation.

\begin{tabular}{lccc}
\hline Sample & $T, \mathrm{~K}$ & $\delta, \mathrm{mm} / \mathrm{s}$ & $\Delta E_{\mathrm{Q}}, \mathrm{mm} / \mathrm{s}$ \\
\hline Ferritin (lyophilized) & 295 & $0.367 \pm 0.011$ & $0.687 \pm 0.011$ \\
Ferritin (lyophilized) & 87 & $0.474 \pm 0.011$ & $0.714 \pm 0.011$ \\
Ferritin (frozen solution) & 87 & $0.477 \pm 0.011$ & $0.701 \pm 0.011$ \\
IDC 3P (lyophilized) & 295 & $0.361 \pm 0.010$ & $0.729 \pm 0.010$ \\
IDC 3P (lyophilized) & 87 & $0.463 \pm 0.013$ & $0.746 \pm 0.013$ \\
IDC 3P (frozen solution) & 87 & $0.455 \pm 0.016$ & $0.717 \pm 0.016$ \\
Imferon (lyophilized) & 295 & $0.358 \pm 0.010$ & $0.704 \pm 0.010$ \\
Imferon (lyophilized) & 87 & $0.460 \pm 0.010$ & $0.740 \pm 0.010$ \\
Imferon (frozen solution) & 87 & $0.457 \pm 0.016$ & $0.707 \pm 0.016$ \\
$\quad$ Fe ${ }^{+2}$ impurity & & $1.276 \pm 0.016$ & $2.509 \pm 0.016$ \\
Rat liver ferritin & 300 & $0.41 \pm 0.01$ & $0.70 \pm 0.02$ \\
$\quad$ freeze-dried) [11] & & & \\
Ferritin (freeze-dried) [23] & 78 & 0.46 & 0.73 \\
Imferon (freeze-dried) [11] & 300 & $0.39 \pm 0.01$ & $0.67 \pm 0.02$ \\
\hline
\end{tabular}
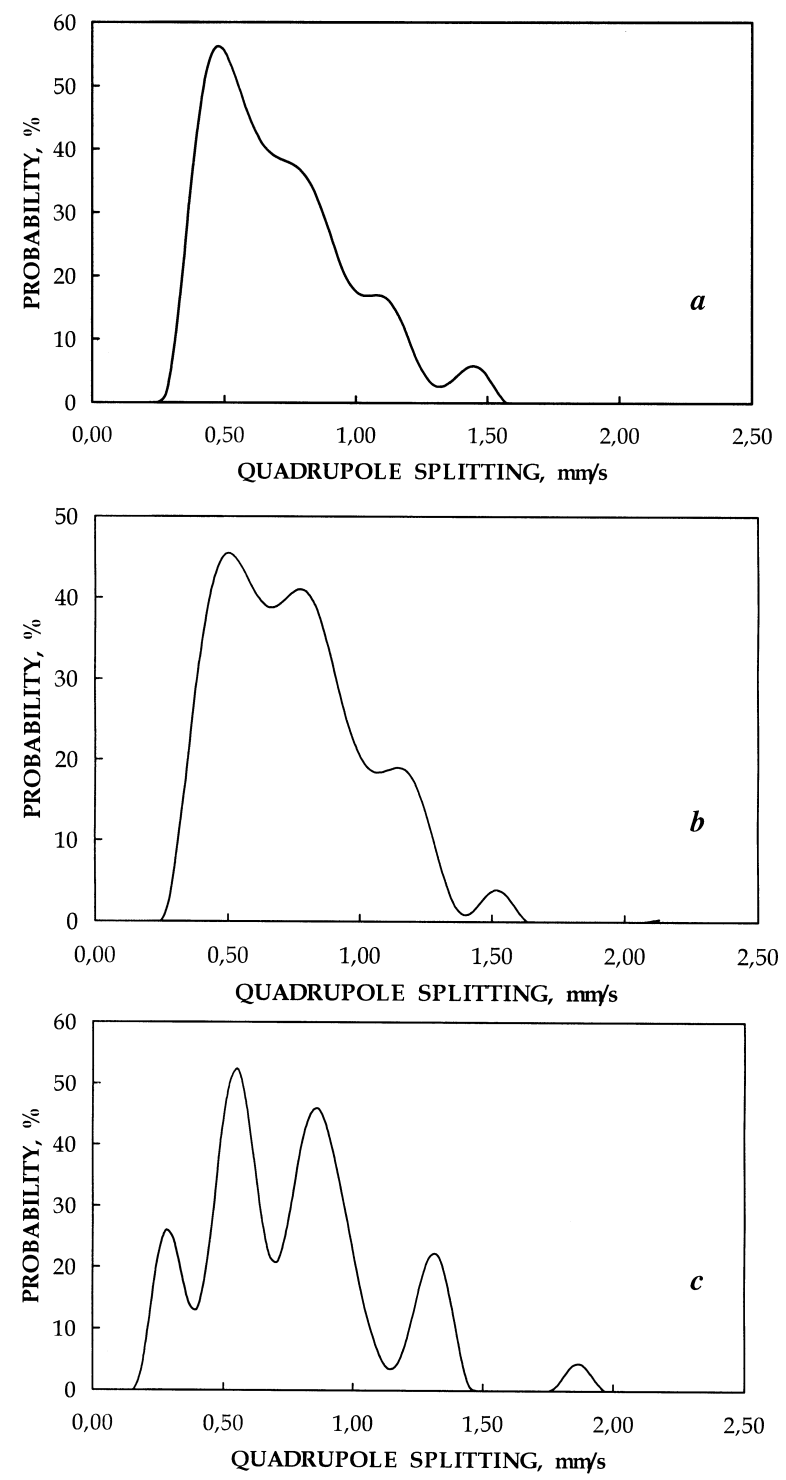

Fig. 3. Distributions of quadrupole splitting for Mössbauer spectra of human liver ferritin: $\mathbf{a}$ - lyophilized form, $T=$ $295 \mathrm{~K} ; \mathbf{b}$ - lyophilized form, $T=87 \mathrm{~K}$; $\mathbf{c}$ - frozen solution, $T=87 \mathrm{~K}$.

\subsection{Ferritin}

Mössbauer spectra of ferritin in lyophilized form and frozen solution are shown in Figure 2. These spectra were fitted by a least squares procedure using various numbers of quadrupole split doublets. The physical sense of the Mössbauer parameters was the major criterium for the number of quadrupole doublets used for better fit. The convergence of the calculation pro- 

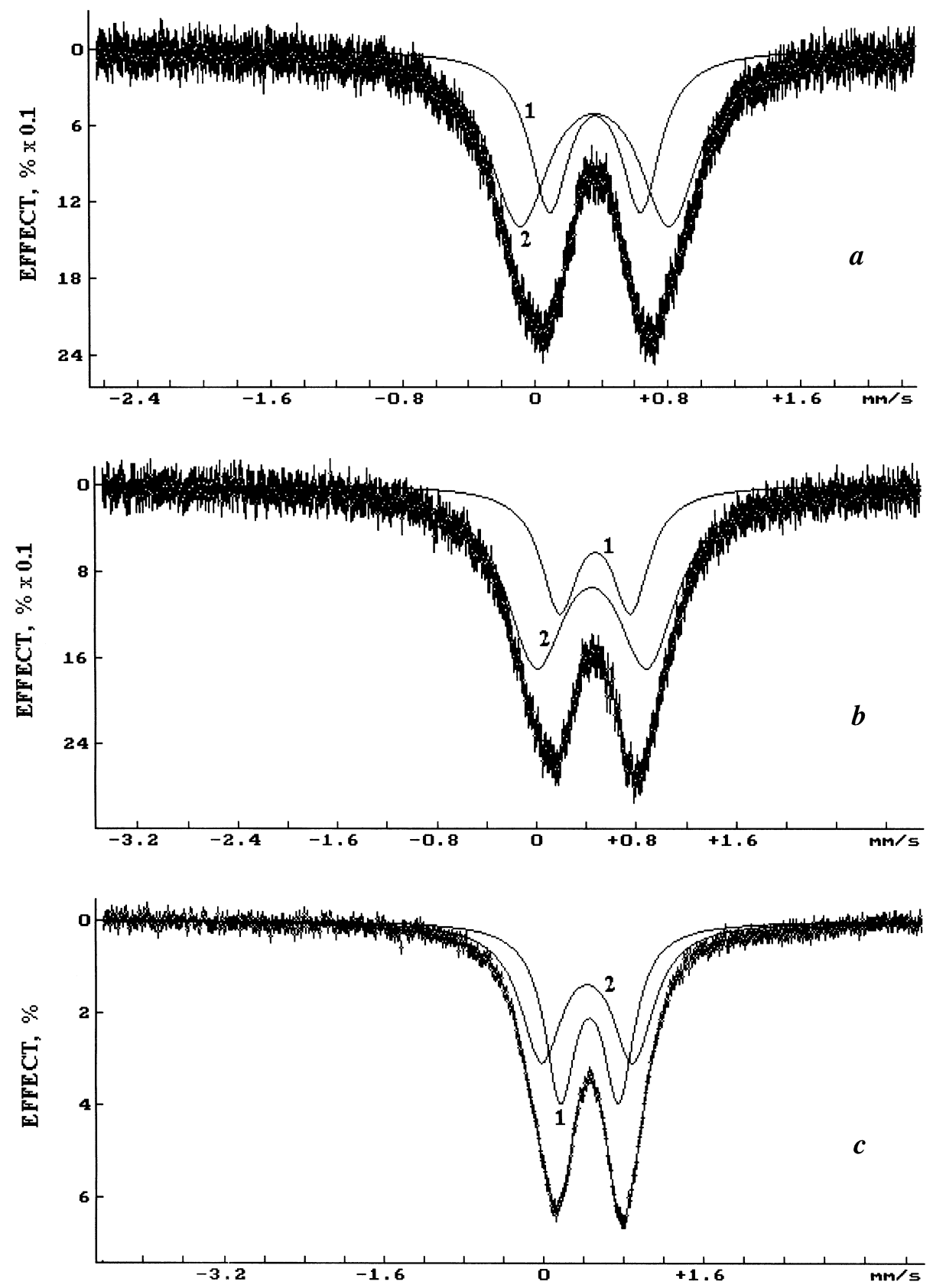

Fig. 4. Mössbauer spectra of IDC3P: a lyophilized form, $T=$ $295 \mathrm{~K} ; \mathbf{b}$ - lyophilized form, $T=87 \mathrm{~K}$; c - frozen solution, $T=87$ K. Continuos lines marked with numbers 1 and 2 indicate a maximal number of quadrupole doublets needed for better fit.

cedure was also taken into account. Different maximal numbers of quadrupole doublets were obtained for better approximation of the measured Mössbauer spectra of ferritin. The room temperature Mössbauer spectrum of lyophilized ferritin was best fitted with five quadrupole doublets as a maximal quantity in superposition with the physical sense of the parameters. However, the liquid nitrogen Mössbauer spec- tra of lyophilized ferritin and ferritin in frozen solution were better fitted with four and three quadrupole doublets, respectively. Mössbauer hyperfine parameters for better fit are given in Table 2. Another fit of Mössbauer spectra of ferritin was made using distribution of quadrupole splitting for comparison. The distribution curves of quadrupole splitting for these spectra are shown in Figure 3. The average values of 
Table 2. Mössbauer hyperfine parameters of human ferritin and iron-dextran complexes obtained by better fit.

\begin{tabular}{lccccc}
\hline Sample & $\begin{array}{c}T, \\
\mathrm{~K}\end{array}$ & $\begin{array}{c}\text { No of } \\
\text { doublet }\end{array}$ & $\begin{array}{c}\delta, \\
\mathrm{mm} / \mathrm{s}\end{array}$ & $\begin{array}{c}\Delta E_{\mathrm{Q}}, \\
\mathrm{mm} / \mathrm{s}\end{array}$ & $\begin{array}{c}S, \\
\%\end{array}$ \\
\hline Ferritin & 295 & 1 & $0.366 \pm 0.011$ & $0.375 \pm 0.011$ & 20 \\
(lyophilized) & & 2 & $0.372 \pm 0.011$ & $0.552 \pm 0.011$ & 24 \\
& & 3 & $0.364 \pm 0.011$ & $0.784 \pm 0.011$ & 38 \\
& & 4 & $0.357 \pm 0.011$ & $1.071 \pm 0.011$ & 14 \\
& & 5 & $0.361 \pm 0.011$ & $1.389 \pm 0.011$ & 4 \\
Ferritin & 87 & 1 & $0.479 \pm 0.011$ & $0.365 \pm 0.011$ & 18 \\
(lyophilized) & & 2 & $0.479 \pm 0.011$ & $0.565 \pm 0.011$ & 18 \\
& & 3 & $0.471 \pm 0.011$ & $0.814 \pm 0.011$ & 45 \\
& & 4 & $0.457 \pm 0.011$ & $1.165 \pm 0.011$ & 19 \\
Ferritin & 87 & 1 & $0.478 \pm 0.011$ & $0.454 \pm 0.011$ & 37 \\
(frozen solution) & & 2 & $0.477 \pm 0.011$ & $0.783 \pm 0.011$ & 41 \\
& & 3 & $0.452 \pm 0.011$ & $1.149 \pm 0.011$ & 22 \\
IDC 3P & 295 & 1 & $0.364 \pm 0.010$ & $0.550 \pm 0.010$ & 39 \\
(lyophilized) & & 2 & $0.359 \pm 0.010$ & $0.905 \pm 0.010$ & 61 \\
IDC 3P & 87 & 1 & $0.479 \pm 0.013$ & $0.569 \pm 0.013$ & 31 \\
(lyophilized) & & 2 & $0.451 \pm 0.013$ & $0.888 \pm 0.013$ & 69 \\
IDC 3P & 87 & 1 & $0.464 \pm 0.016$ & $0.583 \pm 0.016$ & 48 \\
(frozen solution) & & 2 & $0.441 \pm 0.016$ & $0.910 \pm 0.016$ & 52 \\
Imferon & 295 & 1 & $0.355 \pm 0.010$ & $0.413 \pm 0.010$ & 20 \\
(lyophilized) & & 2 & $0.364 \pm 0.010$ & $0.662 \pm 0.010$ & 36 \\
& & 3 & $0.348 \pm 0.010$ & $0.977 \pm 0.010$ & 44 \\
Imferon & 87 & 1 & $0.464 \pm 0.010$ & $0.444 \pm 0.010$ & 29 \\
(lyophilized) & & 2 & $0.460 \pm 0.010$ & $0.796 \pm 0.010$ & 46 \\
& & 3 & $0.451 \pm 0.010$ & $1.151 \pm 0.010$ & 25 \\
Imferon & 87 & 1 & $0.466 \pm 0.016$ & $0.484 \pm 0.016$ & 35 \\
(frozen solution) & & 2 & $0.462 \pm 0.016$ & $0.765 \pm 0.016$ & 40 \\
& & 3 & $0.427 \pm 0.016$ & $1.103 \pm 0.016$ & 21 \\
\multicolumn{1}{c}{ Fe+2 impurity } & & & $1.276 \pm 0.016$ & $2.509 \pm 0.016$ & 4 \\
\hline & & & & &
\end{tabular}

Table 3. Average $\Delta E_{\mathrm{Q}}$ values and values of $\Delta E_{\mathrm{Q}}$ with maximal probability for Mössbauer spectra of human ferritin and iron-dextran complexes obtained with distribution of quadrupole splitting.

\begin{tabular}{lccc}
\hline Sample & $T$, & $\begin{array}{c}\text { Average } \\
\end{array}$ & $\begin{array}{c}\mathrm{Max} \\
\mathrm{K}\end{array}$ \\
& $\Delta E_{\mathrm{Q}}, \mathrm{mm} / \mathrm{s}$ & $\Delta E_{\mathrm{Q}}, \mathrm{mm} / \mathrm{s}$ \\
\hline Ferritin (lyophilized) & 295 & $0.710 \pm 0.017$ & $0.481 \pm 0.013$ \\
Ferritin (lyophilized) & 87 & $0.752 \pm 0.013$ & $0.508 \pm 0.025$ \\
Ferritin (frozen solution) & 87 & $0.763 \pm 0.055$ & $0.550 \pm 0.015$ \\
IDC 3P (lyophilized) & 295 & $0.786 \pm 0.032$ & $0.656 \pm 0.030$ \\
IDC 3P (lyophilized) & 87 & $0.820 \pm 0.083$ & $0.591 \pm 0.021$ \\
IDC 3P (frozen solution) & 87 & $0.810 \pm 0.039$ & $0.664 \pm 0.021$ \\
Imferon (lyophilized) & 295 & $0.749 \pm 0.023$ & $0.547 \pm 0.033$ \\
Imferon (lyophilized) & 87 & $0.789 \pm 0.044$ & $0.837 \pm 0.034$ \\
Imferon (frozen solution) & 87 & $0.736 \pm 0.043$ & $0.519 \pm 0.008$ \\
Horse spleen ferritin & 295 & $0.64 \pm 0.22$ & $0.62 \pm 0.22$ \\
$\quad$ freeze-dried) [10] & & & \\
Imferon (freeze-dried) [10] & 295 & $0.72 \pm 0.26$ & $0.61 \pm 0.26$ \\
\hline
\end{tabular}

$\Delta E_{\mathrm{Q}}$ and the values of $\Delta E_{\mathrm{Q}}$ with maximal probability are given in Table 3 .
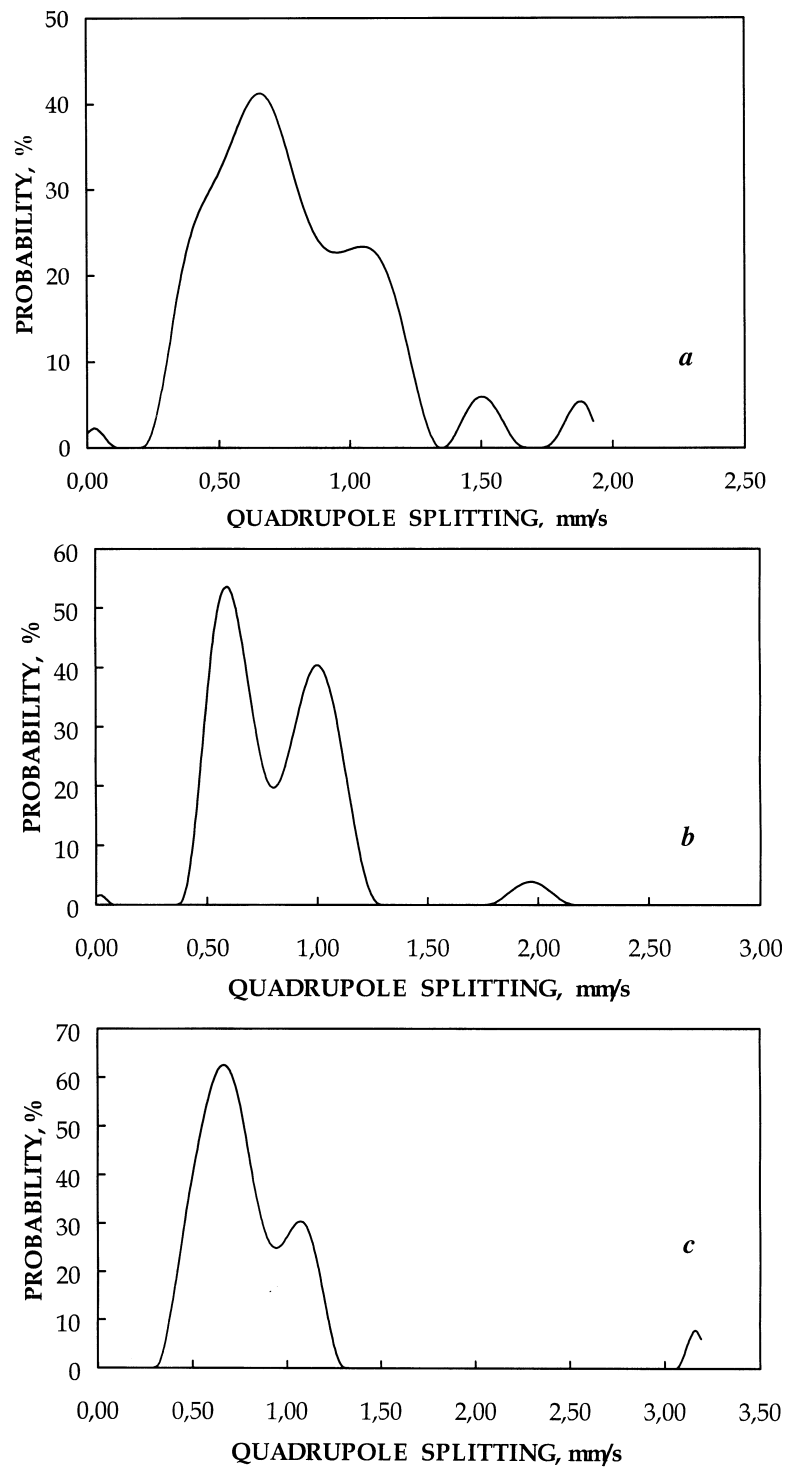

Fig. 5. Distributions of quadrupole splitting for Mössbauer spectra of IDC3P:a - lyophilized form, $T=295 \mathrm{~K}$; $\mathbf{b}-$ lyophilized form, $T=87 \mathrm{~K} ; \mathbf{c}-$ frozen solution, $T=87 \mathrm{~K}$.

\subsection{IDC3P}

Mössbauer spectra of IDC3P samples are shown in Figure 4. The best fit of these spectra was made using the superposition of two quadrupole doublets only. However, the intensity and areas of the high and small quadrupole split doublets were different, as clearly seen in Fig. 4 and from Table 2, where the Mössbauer paramters are collected. Distributions of quadrupole splitting for Mössbauer spectra of IDC3P 

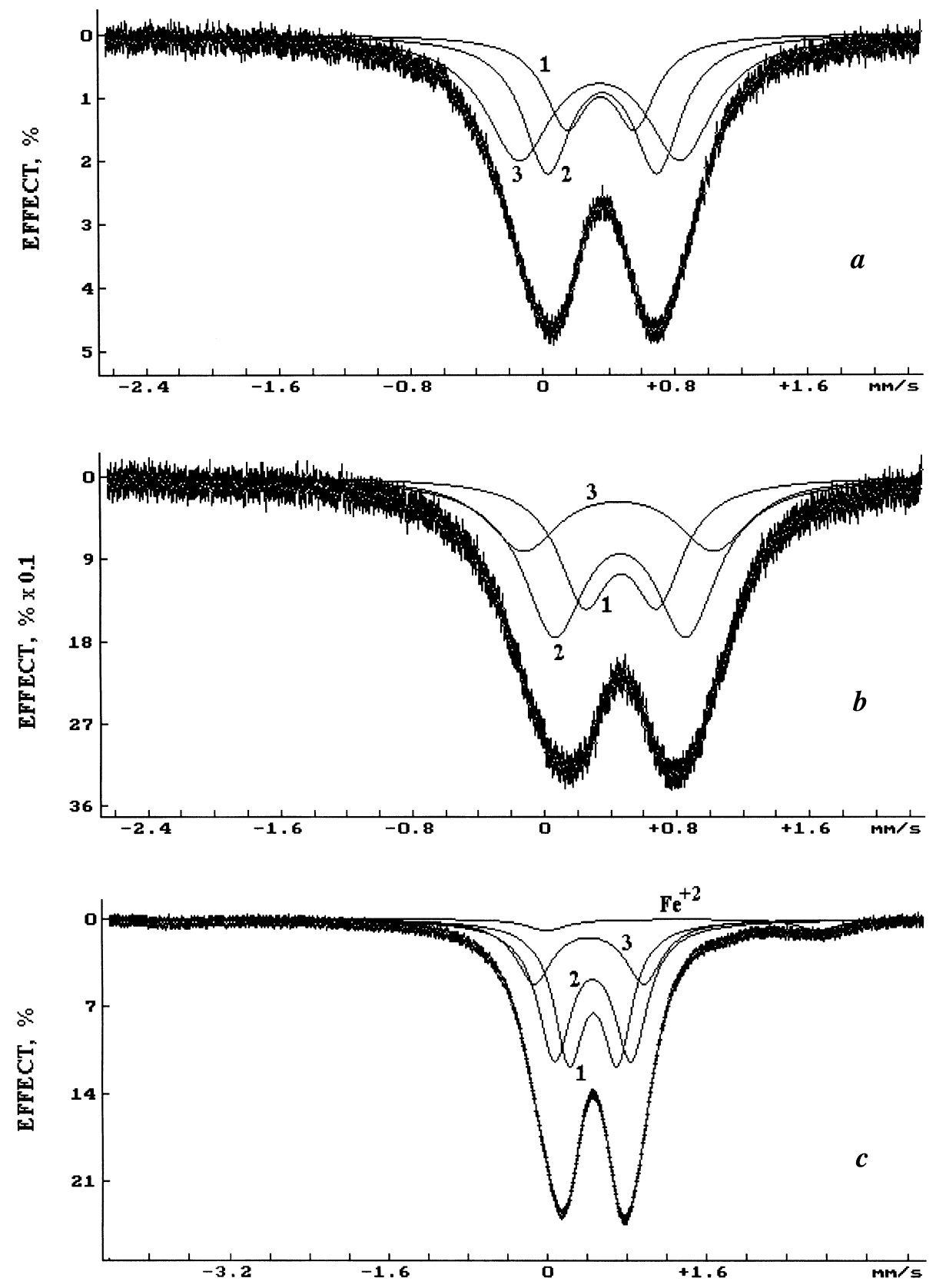

Fig. 6. Mössbauer spectra of Imferon: a lyophilized form, $T=$ $295 \mathrm{~K} ; \mathbf{b}$ - lyophilized form, $T=87 \mathrm{~K}$; c - frozen solution, $T=87 \mathrm{~K}$. Continuos lines marked with numbers 1,2 and 3 indicate a maximal number of quadrupole doublets needed for better fit.

samples are shown in Figure 5. The average values of $\Delta E_{\mathrm{Q}}$ and the values of $\Delta E_{\mathrm{Q}}$ with maximal probability obtained for IDC3P samples are given in Table 3.

\subsection{Imferon}

Mössbauer spectra of lyophilized Imferon and Imferon in frozen solution are shown in Figure 6.
In this case all spectra were better fitted using superposition of three quadrupole doublets. The intensities and areas of corresponding quadrupole doublets were different for Mössbauer spectra of Imferon samples (parameters see in Table 2). Distributions of quadrupole splitting for Mössbauer spectra of Imferon samples are shown in Figure 7. 

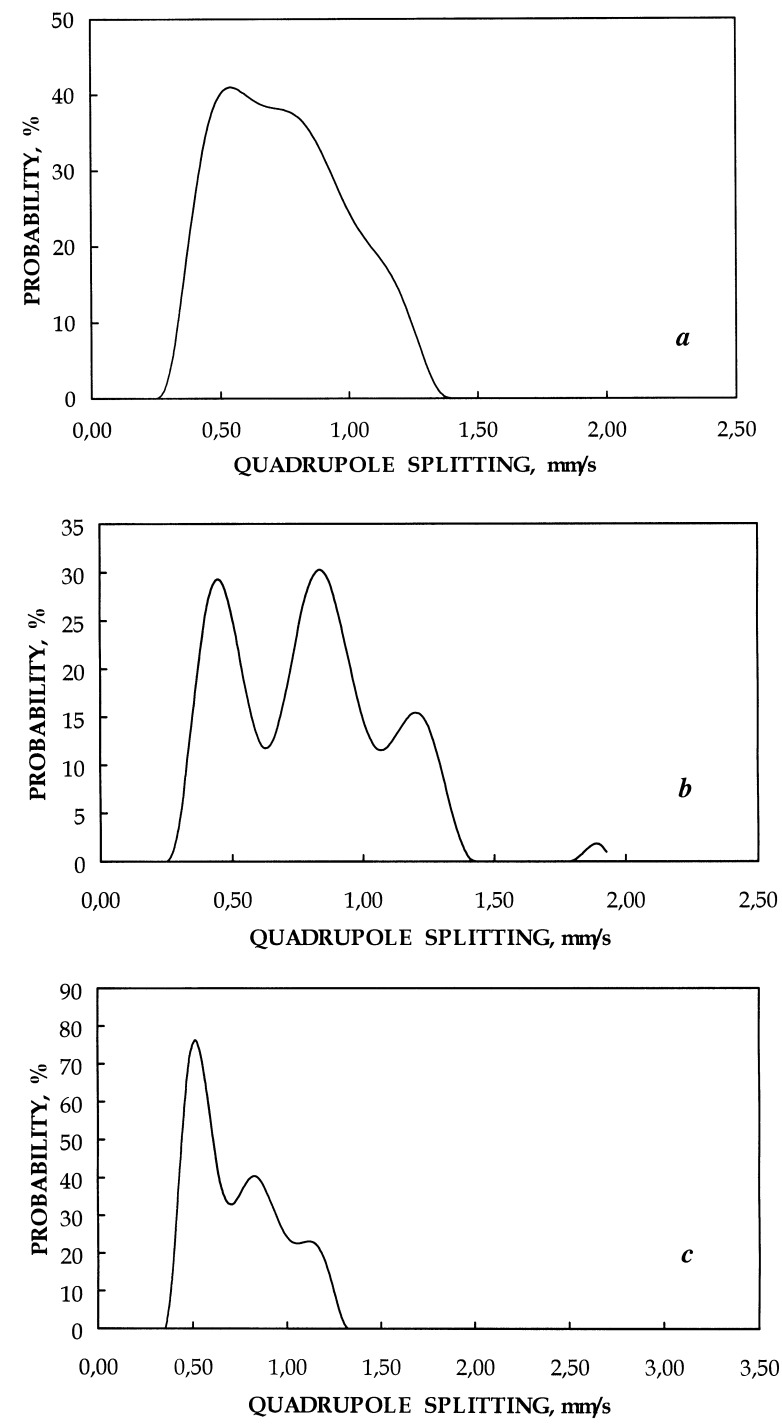

Fig. 7. Distributions of quadrupole splitting for Mössbauer spectra of Imferon: a - lyophilized form, $T=295 \mathrm{~K}$; b - lyophilized form, $T=87 \mathrm{~K}$; $\mathbf{c}-$ frozen solution, $T=87 \mathrm{~K}$.

\section{Discussion}

The results of the fitting of Mössbauer spectra of ferritin and IDC by the least squares procedure showed that various numbers of quadrupole split doublets are needed for better fit. For Mössbauer spectra of IDC3P the maximal quantity of quadrupole doublets was two, while for the Mössbauer spectrum of lyophilized ferritin measured at $295 \mathrm{~K}$ the maxi- mal one rose up to five. If each quadrupole doublet may be related to the core regions with microstructural peculiarities, we may conclude that the different quantities of quadrupole doublets resulting from the best fit reflect microstructural variations in each core. The increase of the quadrupole splitting relates to an increase of the electric field gradient at the ${ }^{57} \mathrm{Fe}$ nuclei that may be the result of the distortion of the symmetry of the iron atom neighbors. In this case the large quadrupole splitting may be related to the high octahedral distortion of the iron-environment in the corresponding core region, while the small quadrupole splitting may be related to the more symmetrical ironenvironment in the core region. The latter region may be considered as a higher crystallinity region.

It was proposed that the IDC3P iron core contained two different regions in solution and lyophilized form as well as at 87 and $295 \mathrm{~K}$, while the Imferon iron core contained three different regions at the same conditions. It should be noted that the area of each quadrupole doublet in the spectra related to the quantity of the ${ }^{57} \mathrm{Fe}$ nuclei in the corresponding region. Therefore, the differences of areas of doublets 1 and 2 for IDC3P Mössbauer spectra (Fig. 4) and those of doublets 1, 2 and 3 for Imferon Mössbauer spectra (Fig. 6) may indicate that the total volume of the corresponding region in each iron core varied with the sample state (lyophilized or solution) and with the temperature of the measurement. On the other hand, the ferritin iron core contained various regions in lyophilized form and solution as well as at 87 and $295 \mathrm{~K}$. The reason of these differences is not clear yet, however it may be the result of some microstructural variations in the core during lyophilization and temperature decrease.

Distributions of quadrupole splitting resulting from additional fitting of Mössbauer spectra of ferritin, IDC3P and Imferon samples demonstrated various types of distribution curves (see Figs. 3, 5 and 7). Some differences of the average values of $\Delta E_{\mathrm{Q}}$ and the values of $\Delta E_{\mathrm{Q}}$ with maximal probability obtained for these samples were also found (see Table 3 ). The average values of $\Delta E_{\mathrm{Q}}$ and $\Delta E_{\mathrm{Q}}$ obtained from one quadrupole doublet fit (Table 1) appeared the same within the errors for several samples. These distributions indicated variations of quadrupole splitting in each sample as a result of continuous heterogeneity of the core structure. There was not any agreement between the results of the better fit using superposition of quadrupole splitting and using distribution of 
quadrupole splitting except for the Mössbauer spectrum of lyophilized Imferon measured at $87 \mathrm{~K}$ (see Figs. $6 \mathrm{~b}$ and Fig. 7 b).

\section{Conclusion}

An analysis of the quadrupole splitting and Mössbauer spectra of human ferritin and some iron-dextran complexes showed heterogeneity of the iron core. We suppose differences of microstructural peculiarities in the iron cores of the studied samples as well as

[1] E. C. Theil, in: Advances in Inorganic Biochemistry, Vol. 5, eds. E. C. Theil, G. L. Eichhorn, and L. G. Marzilli, Elsevier, New York, 1983, p. 1-38.

[2] E. C. Theil, in: Metal Clusters in Proteins, ACS Symp. Series No. 372, ed. L. Que, 1988, p. 179-195.

[3] S. M. Heald, E. A. Stern, B. Bunker, E. M. Holt, and S. L. Holt, J. Am. Chem. Soc. 101, 68 (1979).

[4] E.C. Theil, D. E. Sayers, and M. A. Brown, J. Biol. Chem. 254, 8132 (1979).

[5] K. M. Towe, J. Biol. Chem. 256, 9377 (1981).

[6] J. M. Cowley, D. E. Janney, R. C. Gerkin, and P. R. Buseck, J. Struct. Biol. 131, 210 (2000).

[7] P. R. Marshall and D. Rutherford, J. Colloid Interface Sci. 37, 390 (1971).

[8] S. H. Bell, M. P. Weir, D. P. E. Dickson, J. F. Gibson, G. A. Sharp, and T. J. Peters, Biochim. Biophys. Acta 787, 227 (1984).

[9] T. G. St. Pierre, S. H. Bell, D. P. E. Dickson, S. Mann, J. Webb, G. R. Moore, and R. J. P. Williams, Biochim. Biophys. Acta 870, 127 (1986).

[10] C.-Y. Yang, A. M. Bryan, E. C. Theil, D. E. Sayers, and L. H. Bowen, J. Inorg. Biochem. 28, 393 (1986).

[11] S.C. Andrews, M.C. Brady, A. Treffry, J. M. Williams, S. Mann, M. I. Cleton, W. De Bruijn, and P. M. Harrison, Biol. Metals. 1, 33 (1988).

[12] T. G. St. Pierre, J. Webb, and S. Mann, in: Biomineralization: Chemical and Biochemical Perspectives, eds. S. Mann, J. Webb, and R. J. P. Williams, VCH Verlagsgesellschaft, Weinheim 1989, p. 295-344.

[13] T. G. St. Pierre, K. C. Tran, J. Webb, D. J. Macey, and P. Pootrakul, in: Mechanisms and Phylogeny of Mineralization in Biological Systems, eds. S. Suga, and H. Nakahara, Springer-Verlag, Tokyo, 1991, p. 291-295.

[14] M. I. Oshtrakh, E. A. Kopelyan, V. A. Semionkin, A. B. Livshits, V. E. Krylova, and A. A. Kozlov, Mater. Sci. Forum 105-110, 1679 (1992).

[15] M. I. Oshtrakh, E. A. Kopelyan, V. A. Semionkin, A. B. Livshits, V. E. Krylova, and A. A. Kozlov, Nucl. Instrum. Meth. Phys. Res. B76, 405 (1993).

[16] M. I. Oshtrakh, E. A. Kopelyan, V. A. Semionkin, A. B. Livshits, V. E. Krylova, T. M. Prostakova, and A. A. Kozlov, J. Inorg. Biochem. 54, 285 (1994).

[17] E. M. Coe, L. H. Bowen, R. D. Bereman, and W. T. Monte, Inorg. Chim. Acta 223, 9 (1994). changes of these peculiarities with sample lyophilization and freezing. The better fit of Mössbauer spectra of ferritin, IDC3P and Imferon using a superposition of various number of quadrupole doublets reflects the presence of various regions in the core with microstructural differences of the iron environment. The fit of these Mössbauer spectra with a distribution of quadrupole splitting reflects supposition of continuous heterogeneity of the core. Therefore, further studies of both approaches for better fit of Mössbauer spectra of ferritin and IDC are needed for clarification.

[18] M. I. Oshtrakh, E. A. Kopelyan, V. A. Semionkin, A. B. Livshits, V. E. Krylova, and A. A. Kozlov, J. Radioan. Nucl. Chem. 190, 449 (1995).

[19] E. M. Coe, L. H. Bowen, R. D. Bereman, J. A. Speer, W. T. Monte, and L. Scaggs, J. Inorg. Biochem. 57, 63 (1995).

[20] T. G. St. Pierre, P. Chan, K. R. Bauchspiess, J. Webb, S. Betteridge, S. Walton, and D. P. E. Dickson, Coord. Chem. Rev. 151, 125 (1996).

[21] S. H. Kilcoyne and A. Gorisek, J. Magn. Magn. Mater. 177181, 1457 (1998).

[22] B. Knight, L. H. Bowen, R. D. Bereman, S. Huang, and E. De Grave, J. Inorg. Biochem. 73, 227 (1999).

[23] I. H. A. Rahman, W. Chua-anusorn, J. Webb, D. J. Macey, and T. G. St. Pierre, Anal. Chim. Acta 393, 235 (1999).

[24] S. H. Kilcoyne and J. L. Lawrence, Z. Kristallogr. 214, 666 (1999).

[25] M. I. Oshtrakh, V. A. Semionkin, O. B. Milder, A. B. Livshits, and A. A. Kozlov, in: Spectroscopy of Biological Molecules: New Directions, eds. J. Greve, G. J. Puppels, and C. Otto, Kluwer Academic Publishers, Dordrecht 1999, p. 547-548.

[26] D. P. E. Dickson, J. Magn. Magn. Mater. 203, 46 (1999).

[27] M. I. Oshtrakh, V. A. Semionkin, O. B. Milder, A. B. Livshits, and A. A. Kozlov, Z. Naturforsch. 55a, 186 (2000).

[28] M. I. Oshtrakh, V. A. Semionkin, P. G. Prokopenko, O. B. Milder, A. B. Livshits, and A. A. Kozlov, Int. J. Biol. Macromol. 29, 303 (2001).

[29] E. Murad, L. H. Bowen, G. J. Long, and T. G. Quin, Clay Minerals 23, 161 (1988).

[30] L. H. Bowen and S. B. Weed, in: Chemical Mössbauer Spectroscopy, ed. R. H. Herber, Plenum Publishing Corporation, 1984, p. 217-242.

[31] E. Murad and J.H. Johnston, in: Mössbauer Spectroscopy Applied to Inorganic Chemistry, Vol. 2, ed. G. J. Long, Plenum Publishing Corporation, 1987, p. 507-582.

[32] S. Granic, J. Biol. Chem. 146, 451 (1942).

[33] P. G. Prokopenko, Bull. Exp. Biol. Med. (Moscow) 4, 70 (1982).

[34] P. G. Prokopenko, S. A. Borisenko, G. D. Egunova, N. N. Ivkov, and Yu. S. Tatarinov, Vestnik Russ. State Med. Univ. (Moscow) 3, 45 (1999).

[35] S. M. Irkaev, V. V. Kupriyanov, and V. A. Semionkin, British Patent No 10745 (7 May, 1987). 